minimal bactericidal concentration of amoxycillin was $27 \cdot 4 \mu \mathrm{mol} / 1$ $(10.0 \mu \mathrm{g} / \mathrm{ml})$ but the minimal inhibitory concentration was only $0.07 \mu \mathrm{mol} / 1(0.025 \mu \mathrm{g} / \mathrm{ml})$; the failed prophylaxis against this relatively tolerant pathogen was ascribed to persistent exposure to large inocula. From our data even nine hours after taking amoxycillin serum concentrations exceeding the minimal inhibitory concentration $(0.07 \mu \mathrm{mol} / \mathrm{l})$ were likely but bactericidal concentrations $(27 \cdot 4$ $\mu \mathrm{mol} / \mathrm{l}$ ) would not have occurred. Clearly, even if amoxycillin concentrations exceed the minimal inhibitory concentration for prolonged periods failure to maintain bactericidal values may be critical.

Our study suggests that nine hours after a $3 \mathrm{~g}$ dose of oral amoxycillin syrup (eight hours after dentistry) serum is not necessarily bactericidal against relatively resistant pathogenic strains of viridans streptococci in about half of all patients. Hence whenever the possibility of infection with viridans streptococci warrants a second dose of amoxycillin this should not be left till eight hours after the procedure as recommended hitherto. ${ }^{1}$ By repeating the dose after about four hours, however, more effective prophylaxis may be obtained even against relatively resistant species.

We thank the University of Hong Kong dental and medical faculties and Beecham Pharmaceuticals for financial support and facilitating this work. We are also indebted to Professor C E Renson for his helpful advice and encouragement.

\section{References}

1 Shanson DC, Ashford RFU, Singh J. High dose oral amoxycillin for preventing endocarditis. Br Med F 1980;280:460

Oakley C, Somerville W. Prevention of infective endocarditis. Br Hear f 1981;45:233-5.

3 Bayliss $R$, Clarke $C$, Oakley $C$, Somerville $W$, Whiffield AGW. The teeth and infective endocarditis. Br Heart $\mathcal{F}$ 1983;50:506-12.

4 Glauser MP, Bernard JP, Moreillon P, Francioli P. Successful single dose amoxycillin prophylaxis against experimental endocarditis: evidence of two mechanisms of protection. $\mathcal{J}$ Infect Dis 1983;147:568-75

5 Denning DW, Cassidy $M$, Dougall A, Stewart $\mathrm{H}$. Failure of single dose amoxycillin as prophylaxi against endocarditis. BrMed $\mathcal{F}$ 1984;289:1499-500.

(Accepted 30 September 1986)

\title{
Role of vagal neuropathy in the hyponatraemia of alcoholic cirrhosis
}

\author{
G DECAUX，P CAUCHIE，A SOUPART, M KRUGER， F DELWICHE
}

\begin{abstract}
The hyponatraemia common in decompensated cirrhosis arises in part from secretion of antidiuretic hormone attributed to a decrease in effective blood volume. Baroreceptors send inhibitory impulses to the midbrain and hypothalamus through the vagus and glossopharyngeal nerves. Since vagal neuropathy often occurs in chronic alcoholism, this might theoretically contribute to the inappropriate secretion of antidiuretic hormone, which might in turn induce hyponatraemia. In a prospective study including 34 patients with cirrhosis a high incidence of vagal neuropathy was found in the alcoholics $(64 \%)$ and a clear cut increase in the incidence of hyponatraemia in patients with evidence of vagal damage and ascites (seven of eight patients $(88 \%) ; p=0.02)$. Results of a retrospective study of 64 patients with cirrhosis and ascitic decompensation showed hyponatraemia in $17(50 \%)$ of 34 alcoholics but in only four $(13 \%)$ of 30 patients with non-alcoholic disease $(p=0.006)$.

Vagal neuropathy in alcoholic cirrhosis may contribute to the low serum sodium concentrations commonly found in these patients.
\end{abstract}

\footnotetext{
Department of Internal Medicine, University Hospital Erasme, and the Institute of Interdisciplinary Research, School of Medicine, Free University of Brussels, Brussels, Belgium

G DECAUX, MD, PHD, assistant

A SOUPART, MD, assistant

F DELWICHE, MD, assistant
}

University Hospital Saint-Pierre, Free University of Brussels, Brussels, Belgium

P CAUCHIE, MD, assistant, department of internal medicine

M KRUGER, MD, assistant, department of neurology

Correspondence to: Dr G Decaux, Service de Medecine Interne, Hôpital Universitaire Erasme, 808 Route de Lennik, 1070 Bruxelles, Belgium.

\section{Introduction}

The hyponatraemia commonly found in cirrhosis is generally attributed to an excessive secretion of antidiuretic hormone despite hypo-osmolality of the blood. ${ }^{1}$ The classical theory suggests that patients with decompensated disease have a decrease in the "effective" central blood volume resulting in decreased vagal and glossopharyngeal afferent influx to the midbrain and hypothalamus. The decreased afferent neural input is associated with a non-osmotic release of antidiuretic hormone and increased sympathetic activity. ${ }^{23}$ All published studies on hyponatraemia in cirrhosis have disregarded any alcoholic origin of the cirrhosis.

A high incidence of vagal neuropathy in chronic alcoholism has recently been described, ${ }^{4}$ which may have a role in inappropriate secretion of antidiuretic hormone. ${ }^{2}$ We decided to investigate this hypothesis systematically in patients with alcoholic and nonalcoholic cirrhosis and report here our results.

\section{Patients and methods}

We studied prospectively 34 consecutive patients (mean age 50 (SD 8 ) years) with normal renal function and histologically proved liver cirrhosis; 25 were alcoholics and nine had posthepatitic disease. All patients had a serum creatinine concentration below $97 \mu \mathrm{mol} / 1(1 \cdot 1 \mathrm{mg} / 100 \mathrm{ml})$ and a total bilirubin concentration below $50 \mu \mathrm{mol} / 1(2.9 \mathrm{mg} / 100 \mathrm{ml})$. From at least 10 days before the study all patients and controls were medication free and (except for 18 patients with ascites) taking a normal hospital diet providing $50-100 \mathrm{mmol}(\mathrm{mEq})$ sodium daily; patients with ascites received a low salt $\operatorname{diet}(10-20 \mathrm{mmol}$ sodium daily). Intake of water was unrestricted and in all cases exceeded 2 litres a day. All the patients were clinically stable. None had signs of liver encephalopathy, evidence of infection, history of recent gastrointestinal bleeding, or diabetes. The alcoholic patients had not touched alcohol for at least 10 days before the tests of autonomic function.

Subjects were assessed for vagal neuropathy by measuring the heart rate response to standing, ${ }^{5}$ deep breathing, ${ }^{6}$ and atropine. ${ }^{4}$ Normal limits were established by studying an abstinent control population of 34 inpatients of similar age and sex who were free of any disease or medication known to interfere with vagal function. 
Response to standing - The R-R intervals were determined at beats 15 and 30 after standing and expressed as the $30: 15$ ratio. A ratio above 1.03 was regarded as normal.

Deep breathing-After at least 10 minutes' recumbency the heart rate was monitored continuously for at least one minute at a paper speed of $50 \mathrm{~mm} / \mathrm{s}$ while the subject breathed deeply. The subject then breathed deeply six to eight times a minute and the difference in mean maximum heart rate between inspiration and expiration was determined. A difference of 10 beats or more/min was considered normal.

The atropine test was performed last. After at least five minutes' recumbency $1.8 \mathrm{mg}$ atropine was given intravenously with an interval of one minute between successive $0.6 \mathrm{mg}$ doses. A minimum increase in heart rate of 20 beats/min was considered normal.

Vagal neuropathy was recorded arbitrarily if the subject had an abnormal result in at least two tests, one of which had to be the atropine test. ${ }^{4}$ Hyponatraemia was defined as a serum sodium concentration below $135 \mathrm{mmol}(\mathrm{mEq}) / 1$ on the morning of the tests. of whom all had been drinking more than $100 \mathrm{~g}$ alcohol daily before admission-and 30 had histologically proved non-alcoholic cirrhosis.

Statistical analysis was by Fisher's exact probability test for small numbers and Student's $t$ test, as appropriate. ${ }^{7}$

\section{Results}

\section{PROSPECTIVE STUDY}

All patients with non-alcoholic cirrhosis had normal vagal function. By contrast, 16 of the 25 alcoholic patients (64\%) showed vagal impairment (fig 1). The presence of vagal damage was not associated with hyponatraemia (serum sodium concentration below $135 \mathrm{mmol} / \mathrm{l}$ ) in the group without ascites (fig 1). In the group with ascitic cirrhosis, however, seven of the eight alcoholics with vagal impairment were hyponatraemic compared with only two of the 10 patients with normal vagal function (fig 1 ) (Fisher's exact test,

Age and biochemical characteristics of 64 patients with alcoholic and non-alcoholic cirrhosis and ascites. Values are means (SD)

\begin{tabular}{|c|c|c|c|}
\hline & $\begin{array}{l}\text { Patients with alcoholic cirrhosis and ascites } \\
\qquad(\mathrm{n}=34)\end{array}$ & $\begin{array}{l}\text { Patients with non-alcoholic cirrhosis and ascites } \\
\qquad(\mathrm{n}=30)\end{array}$ & $\begin{array}{c}\text { p Value } \\
\text { (Student's } t \text { test) }\end{array}$ \\
\hline Age (years) & $59 \cdot 0(9 \cdot 0)$ & $58 \cdot 0(9 \cdot 0)$ & NS \\
\hline Serum sodium $(\mathrm{mmol} / \mathrm{l})$ & $134 \cdot 4(5 \cdot 0)$ & $138 \cdot 7(4 \cdot 8)$ & $\mathrm{p}<0.01$ \\
\hline Blood urea $(\mathrm{mmol} / \mathrm{l})$ & $4 \cdot 0(2 \cdot 0)$ & $5 \cdot 7(2 \cdot 1)$ & $\mathrm{p}<0.01$ \\
\hline Creatinine $(\mu \mathrm{mol} / \mathrm{l})$ & $72 \cdot 5(15 \cdot 0)$ & $73 \cdot 3(15 \cdot 0)$ & NS \\
\hline Aspartate aminotransferase (IU/ml; normal 7-25) & $57 \cdot 5(35 \cdot 0)$ & $72 \cdot 3(72 \cdot 0)$ & NS \\
\hline Alanine aminotransferase (IU/l; normal 1-25) & $29 \cdot 7(18 \cdot 0)$ & $69 \cdot 3(95 \cdot 0)$ & NS \\
\hline Bilirubin $(\mu \mathrm{mol} / \mathrm{l})$ & $56 \cdot 4(54 \cdot 4)$ & $63 \cdot 3(61 \cdot 5)$ & NS \\
\hline Albumin $(\mathrm{mmol} / \mathrm{l})$ & $0.46(0.08)$ & $0.49(0.09)$ & NS \\
\hline Prothrombin time (s) & $15 \cdot 0(1 \cdot 5)$ & $14 \cdot 5(2 \cdot 0)$ & NS \\
\hline
\end{tabular}

Conversion: SI to traditional units-Sodium: $1 \mathrm{mmol} / 1=1 \mathrm{mEq} / \mathrm{l}$. Blood urea: $1 \mathrm{mmol} / \approx \approx \mathrm{mg} / 100 \mathrm{ml}$. Creatinine: $1 \mu \mathrm{mol} / 1 \approx 0 \cdot 01 \mathrm{mg} / 100 \mathrm{ml}$. Bilirubin: $1 \mu \mathrm{mol} / \mathrm{l} \approx 0.06 \mathrm{mg} / 100 \mathrm{ml}$. Albumin: $1 \mathrm{mmol} / 1 \approx 6.4 \mathrm{mg} / 100 \mathrm{ml}$.

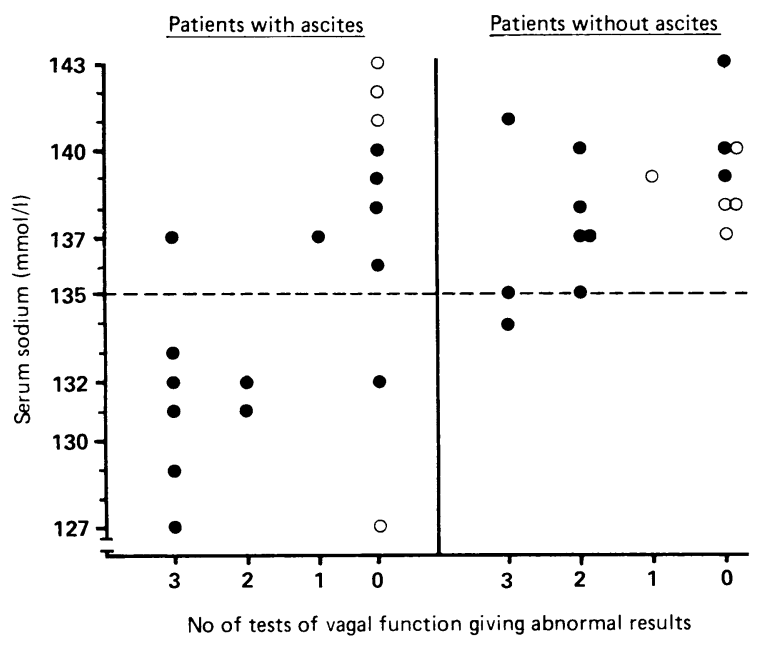

FIG 1-Numbers of tests of vagal function giving abnormal result in relation to serum sodium concentrations in patients with alcoholic cirrhosis $(\bullet)$ and non-alcoholic cirrhosis $(0)$ with and without ascites. Dashed line represents lower limit of normal serum sodium concentration. (Sodium: $1 \mathrm{mmol} / \mathrm{l}=1 \mathrm{mEq} / \mathrm{l}$.)

To study the possible role of hyponatraemia in upsetting vagal function the same tests were performed in five patients with asymptomatic hyponatraemia (serum sodium concentration below $128 \mathrm{mmol} / \mathrm{l}$ ) related to a syndrome of inappropriate secretion of antidiuretic hormone of neoplastic origin. These five patients were free of medication, abstinent, and did not have diabetes or evidence of cardiac or liver dysfunction.

All subjects in the prospective study gave informed consent. Other patients admitted to hospital with decompensated disease-that is, with ascites-during 1981-4 were analysed retrospectively from the case notes.

Only patients not receiving diuretics and without a history of renal failure, heart failure, gastrointestinal bleeding, diabetes, or infection were accepted for the retrospective study. Serum sodium concentrations were expressed as the mean of several determinations obtained after at least five days in hospital. Thirty four patients had histologically proved alcoholic cirrhosis- $p=0.02$ ). Among the 14 alcoholic patients with decompensated disease (fig 1) only one of the six with normal vagal function had hyponatraemia (Fisher's exact test, $\mathrm{p}=0.04$ ).

Heart rate measured before the injection of atropine in ascitic patients with vagal neuropathy was significantly higher (mean 91 (SD 10) beats $/ \mathrm{min}$ ) than in patients with normal vagal function $(79(8)$ beats $/ \mathrm{min} ; \mathrm{p}<0.01)$ despite similar mean blood pressures (88 (SD 9) and 85 (10) $\mathrm{mm} \mathrm{Hg}$, respectively).

Biochemical findings reflecting the degree of liver failure (serum aspartate and alanine aminotransferase activities, total bilirubin concentration, prothrombin time (Quick's test)) were similar in patients with alcoholic and non-alcoholic decompensated disease whether or not there was also vagal damage.

All patients with vagal degeneration had more pronounced clinical features of peripheral neuropathy (partial or complete abolition of ankle jerks, loss of vibration sense $(128 \mathrm{~Hz})$ at the ankles) as compared with the group with normal vagal function. No patient had orthostatic hypotension. Results of the three tests of vagal function were normal in the five patients with hyponatraemia secondary to the syndrome of inappropriate secretion of antidiuretic hormone.

\section{RETROSPECTIVE STUDY}

Retrospective analysis of data from the 64 patients admitted with alcoholic and non-alcoholic decompensated cirrhosis showed higher mean sodium and urea concentrations in the non-alcoholic patients despite similar biochemical features of liver failure in the two groups (see table). Seventeen of the 34 alcoholics $(50 \%)$ had a serum sodium concentration below $135 \mathrm{mmol} / \mathrm{l}$ (fig 2), whereas this was true for only four of the 30 non-alcoholic patients $(13 \%)$ (Fisher's exact test, $\mathrm{p}=0.006$ ).

\section{Discussion}

There are numerous mechanisms in the development of hyponatraemia in cirrhosis, but the main one seems to be secretion of antidiuretic hormone by the posterior pituitary, generally attributed to a decrease in "effective" blood volume. ${ }^{1}$ In cirrhosis a specific decrease in effective blood volume secondary to peripheral 
vasodilatation, hypoalbuminaemia, and venous pooling would be expected to stimulate the baroreceptors in the left atrium and carotid sinus. This would cause a decrease in vagal and glossopharyngeal inhibitory input to the midbrain and hypothalamus resulting in release of antidiuretic hormone and enhanced sympathetic nerve activity. ${ }^{3}$ For this physiological adjustment to occur the glossopharyngeal and vagus nerves must be functionally normal. Hence vagal damage, by decreasing the inhibitor influx to the hypothalamus, might be expected to cause an excessive secretion of antidiuretic hormone.

We did not find an increased incidence of hyponatraemia in our alcoholic patients with vagal neuropathy and no ascites. This agrees with the well known rarity of hyponatraemia in cirrhosis without ascites. In patients with vagal degeneration and ascites, however, we found a clear cut increase in the frequency of hyponatraemia.

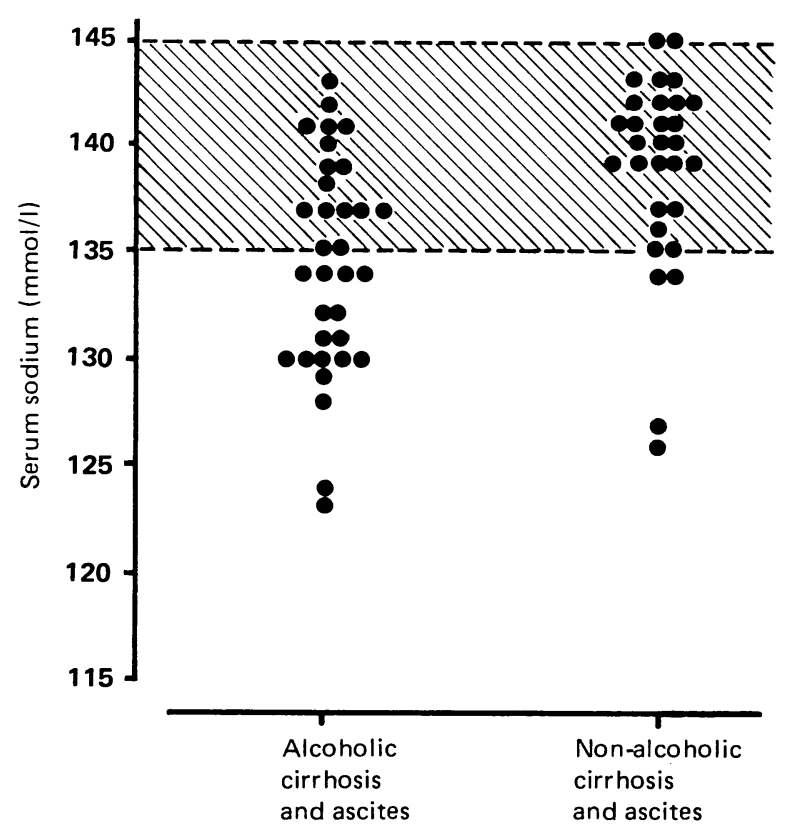

FIG 2-Serum sodium concentrations in 64 patients with alcoholic and non-alcoholic cirrhosis and ascites. Shaded area represents normal range in our hospital.

Comparison between numbers in the two groups with concentrations below $135 \mathrm{mmol}(\mathrm{mEq}) / 1: \mathrm{p}=0.006$ (Fisher's exact test).
Moreover, these patients had a higher heart rate than the group with a functionally normal vagus nerve, which might reflect, for instance, hypovolaemia or a lesion of the vagus nerve.

We emphasise that biochemical parameters of liver function were similar in the two groups except for a lower blood urea concentration in the alcoholics, which was probably related to a more frequent increase in the effective vascular volume in these patients. ${ }^{78}$ Since the hyponatraemia related to the syndrome of inappropriate secretion of antidiuretic hormone was not associated with abnormal vagal function in the five patients studied, it is unlikely that hyponatraemia by itself would have affected the tests of vagal function.

If the high incidence of vagal neuropathy in alcoholic cirrhosis plays a part in the inappropriate secretion of antidiuretic hormone we should expect to find a lower frequency of hyponatraemia in nonalcoholic cirrhosis-and that was indeed the case in our retrospective study. The discrepancy in the incidence of hyponatraemia between the alcoholic and non-alcoholic patients could not be explained by more severe liver failure in the first group as the biochemical findings were similar.

Before attributing increased sympathetic activity and excessive secretion of antidiuretic hormone to a decrease in blood volume in cirrhosis $^{3}$ it seems important to exclude impaired vagal function, which may contribute to hyponatraemia independently of any contraction of effective blood volume. ${ }^{910}$

\section{References}

I Bichet D, Szatalowicz VL, Charmovitz C, Schrier RW. Role of vasopressin in abnormal wate excretion in cirrhotic patients. Ann Intern Med 1982;96:413-7.

2 Schrier RW, Berl T. Mechanism of the antidiuretic effect associated with interruption of parasympathetic pathways. $\mathcal{F}$ Clin Invest 1972;51:2613-20.

3 Bichet DG, Van Putten VJ, Schrier RW. Potential role of increased sympathetic activity in impaired sodium and water excretion in cirrhosis. $N$ Engl f Med 1982;307:1552-7.

4 Duncan G, Johnson RH, Lambie DG, Whiteside EA. Evidence of vagal neuropathy in chronic alcoholics. Lancet 1980;ii:1053-7.

5 Ewing DJ, Campbell JW, Murray A, Neilson JMM, Clarke BF. Immediate heart-rate response to standing: simple test for autonomic neuropathy in diabetes. Br Med 7 1978;i:145-7.

6 Wheeler T, Watkins PJ. Cardiac denervation in diabetes. Br Med 7 1973;iv:584-6.

7 Decaux G, Dumont I, Naeije N, Mols P, Melot C, Mockel J. High uric acid and urea clearance in irrhosis secondary to increased "effective vascular volume." Am J Med 1982;73:328-34.

8 Decaux G, Genette F, Mockel J. Hypouremia in the syndrome of inappropriate secretion of antidiuretic hormone. Ann Intern Med 1980;93:716-7.

9 Lieberman FL, Ito S, Reynolds TB. Effective plasma volume in cirrhosis with ascites. Evidence that a decreased value does not account for renal sodium retention, a spontaneous reduction in glomerular filtration rate (GFR) and a fall in GFR during drug-induced diuresis. $\mathcal{F}$ Clin Inves 1969;48:975-81.

$10 \mathrm{Levy} M$. Sodium retention and ascites formation in dogs with experimental portal cirrhosis. $A m \mathcal{F}$ Physiol 1977;233:F572-85.

(Accepted 16 October 1986)

\section{SHORT REPORTS}

\section{Effectiveness of intravenous acyclovir in immunocompetent patient with herpes zoster encephalitis}

Herpes zoster associated encephalitis is a rare complication of a common cutaneous disorder. We report on an immunocompetent patient with herpes zoster associated encephalitis who responded rapidly to treatment with intravenous acyclovir.

\section{Case report}

A 69 year old widow was admitted with a two week history of severe left sided facial pain followed a few days later by left sided vesicular skin lesions on the face and ulcers on the left side of her tongue. She was anorectic, nauseated, and in great pain. She had had chickenpox at the age of 24 while pregnant with her third child; her son had developed severe neonatal varicella. She was healthy and was admitted primarily for rehydration and pain relief.

On admission she was unwell but afebrile, alert, and fully oriented with no meningism or abnormal neurological signs. She had a typical zoster rash in the maxillary and mandibular divisions of the left trigeminal nerve and large whitish ulcers along the left border of her tongue and soft palate. The results of initial investigations showed normal haematological indices and concentrations of electrolytes and random blood glucose, but her erythrocyte sedimentation rate was $47 \mathrm{~mm}$ in the first hour and her blood urea concentration was increased $(10.1 \mathrm{mmol} / \mathrm{l}(60.7 \mathrm{mg} / 100 \mathrm{ml}))$.

On the second evening after admission she first experienced severe visual hallucinations, continuous when her eyes were shut but suppressed when they were open, with delusions of paranoia and grandeur. A few hours later she developed unsteadiness of gait and vertigo. She became feverish (temperature $38 \cdot 5^{\circ} \mathrm{C}$ ) but remained conscious, with a mental test score of $10 / 10$ on the modified Newcastle scale. Neurological examination showed complex nystagmus, gross truncal ataxia, bilateral abducent nerve palsies, complete left lower motor neurone facial weakness, sensorineural deafness in the left ear, hypoaesthesia of all three divisions of the left trigeminal nerve, and an absent left corneal reflex.

On lumbar puncture the cerebrospinal thuid contained 120 white blood cells/ml, with $95 \%$ lymphocytes. Cerebrospinal fluid glucose concentration was low $(2 \cdot 1 \mathrm{mmol} / 1(37 \cdot 8 \mathrm{mg} / 100 \mathrm{ml})$ compared with a simultaneous blood glucose concentration of $5.2 \mathrm{mmol} / 1(93.6 \mathrm{mg} / 100 \mathrm{ml}))$, and cerebrospinal fluid protein concentration was increased at $1 \cdot 29($ normal $0 \cdot 3-0 \cdot 5) \mathrm{g} / \mathrm{l}$. The zoster titre was $1 / 16$ in the cerebrospinal fluid and 1:1024 in serum. An electroencephalogram showed moderate generalised disorganisation consistent with encephalitis while a computed tomogram was normal. The results of Mantoux and candidal skin tests and serum immunoglobulin concentrations were normal. In view of these and her 